\title{
PENGGUNAAN INTERNET DI DALAM PENGAJARAN MATA KULIAH BAHASA INGGRIS DI LINGKUNGAN INSTITUT PENDIDIKAN INDONESIA (IPI) GARUT
}

\author{
Irsyad Nugraha \\ Fakultas Pendidikan Bahasa dan Sastra \\ Institut Pendidikan Indonesia (IPI) Garut, Indonesia \\ irsyadnugraha@institutpendidikan.ac.id
}

\begin{abstract}
English as an International Language has been widely used as a tool to communicate in various fields. Because of its function as an International Language, English is much studied by foreign speakers in both formal and non-formal education. Along with the development of science and technology, various teaching methods and teaching and learning media have been created and applied in teaching and learning English. Internet as a medium of information and global communication is very likely applied as a medium of learning foreign languages, especially English. Based on the study of literature on the use of the Internet as learning English can be concluded that the internet is highly recommended as a medium of learning and teaching English at various levels of Education, especially in the level of college is very closely related to technological advances and how to communicate well using a foreign language. In addition, the Internet provides abundant learning and teaching resources to be used as a source and medium of learning English. However, the use of the Internet as a medium of learning English is also experiencing difficulties, especially the cost of installation and access.
\end{abstract}

Keywords: English, Internet, learning media and teaching.

Abstrak - Bahasa Inggris sebagai Bahasa Internasional telah banyak digunakan sebagai alat untuk berkomunikasi di berbagai bidang. Karena fungsinya sebagai Bahasa Internasional maka Bahasa Inggris banyak dipelajari oleh penutur asing baik di lingkungan Pendidikan formal maupun non - formal. Seiring dengan perkembangan ilmu pengetahuan dan tekhnologi, maka berbagai metode pengajaran dan media pengajaran dan pembelajaran telah diciptakan dan diterapkan dalam pengajaran dan pembelajaran Bahasa Inggris. Internet sebagai media informasi dan komunikasi global sangat mungkin diterapkan sebagai media pembelajaran Bahasa asing, terutama Bahasa Inggris. Berdasarkan kajian literature tentang pemakaian Internet sebagai pembelajaran Bahasa Inggris dapat disimpulkan bahwa internet sangat disarankan sebagai media pembelajaran dan pengajaran Bahasa Inggris di berbagai jenjang Pendidikan terutama di jenjang Perguruan tinggi yang sangat erat kaitannya dengan kemajuan tekhnologi dan bagaimana berkomunikasi dengan baik menggunakan bahasa asing. Selain itu Internet menyediakan sumber - sumber pembelajaran dan pengajaran yang berlimpah untuk bisa digunakan sebagai sumber maupun media pembelajaran Bahasa Inggris. Namun demikian, pemakaian internet sebagai media pembelajaran Bahasa Inggris juga mengalami kendala terutama biaya instalasi dan aksesnya.

Kata kunci: Bahasa Inggris, Internet, media pembelajaran dan pengajaran. 


\section{PENDAHULUAN}

Bahasa Inggris sangatlah mendominasi di era global ini dan tidak dapat dihindari oleh kita semua. Sebagai Bahasa global dunia, Bahasa Inggris telah digunakan sebagai alat komunikasi dalam berbagai bidang: diplomasi, komunikasi internasional, bisnis, pariwisata, Pendidikan, ilmu pengetahuan, tekhnologi komputer, media dan internet. Bahkan karena pemanfaatannya untuk mengembangkan komunikasi, teknologi, pemrograman, perangkat lunak dan lain sebagainya, Bahasa Inggris telah mendominasi web dimana sebesar $70 \%$ dari seluruh informasi yang ada di web ditulis dalam Bahasa Inggris.( Boyanova, 2011).

Karena fungsinya sebahai Bahasa komunikasi internasional, Bahasa Inggris berusaha dipelajari oleh penutur asing baik dalam lingkungan Pendidikan formal maupun non-formal. Seiring dengan perkembangan ilmu pengetahuan dan teknologi, berbagai metode dan media pembelajaran telah diciptakan dan diterapkan dalam pembelajaran Bahasa Inggris. Dalam literatur metode atau pendekatan pembelajaran Bahasa Inggris dikenal dua pendekatan yang berbeda berdasarkan hubungan antara dosen dan mahasiswa. Dua pendekatan itu adalah pendekatan dosen aktif (teacher - centered) dan pendekatan mahasiswa aktif (learner centered) (Alatis and James, 2010). Perbedaan antara kedua pendekatan pembelajaran Bahasa tersebut ditunjukan pada table 1 .

\begin{tabular}{|c|c|}
\hline Teacher - Centered & Learner - Centered \\
\hline Focus is on instructor & $\begin{array}{l}\text { Focus is on both students } \\
\text { and instructor }\end{array}$ \\
\hline $\begin{array}{l}\text { Focus is on language } \\
\text { forms and structures } \\
\text { (what the instructor } \\
\text { knows about the } \\
\text { language) }\end{array}$ & $\begin{array}{l}\text { Focus is on language use } \\
\text { in typical situations } \\
\text { (how students will use } \\
\text { the language) }\end{array}$ \\
\hline $\begin{array}{l}\text { Instructor talks; students } \\
\text { listen }\end{array}$ & $\begin{array}{l}\text { Instructor models, } \\
\text { students interact with } \\
\text { instructor and one } \\
\text { another }\end{array}$ \\
\hline Students work alone & $\begin{array}{l}\text { Students work in pairs, } \\
\text { in groups, or alone } \\
\text { depending on the } \\
\text { purpose of the activity }\end{array}$ \\
\hline $\begin{array}{l}\text { Instructor monitors and } \\
\text { corrects every student } \\
\text { utterance }\end{array}$ & $\begin{array}{lr}\begin{array}{l}\text { Students talk } \\
\text { constant }\end{array} & \text { without } \\
\text { monitoring; } & \text { instructor } \\
\text { provides } & \text { feedback/ } \\
\text { corrections } & \text { when } \\
\text { questions arise } & \end{array}$ \\
\hline $\begin{array}{l}\text { Instructor answers } \\
\text { students' questions } \\
\text { about language }\end{array}$ & $\begin{array}{l}\text { Students answer each } \\
\text { other's questions, using } \\
\text { instructor as an } \\
\text { information resource }\end{array}$ \\
\hline $\begin{array}{l}\text { Instructor chooses } \\
\text { topics }\end{array}$ & $\begin{array}{l}\text { Students have some } \\
\text { choice of topics }\end{array}$ \\
\hline $\begin{array}{l}\text { Instructor evaluates } \\
\text { students learning }\end{array}$ & $\begin{array}{l}\text { Students evaluate their } \\
\text { own learning; instructor } \\
\text { also evaluates }\end{array}$ \\
\hline Classroom is quiet & $\begin{array}{l}\text { Classroom is often noisy } \\
\text { and busy }\end{array}$ \\
\hline
\end{tabular}

Tabel 1. Perbedaan antara pendekatan teacher-centered dan Learner - centered

Perkembangan teknologi juga berpengaruh pada media pembelajaran Bahasa Inggris. Menurut Menurut Dryden, Gordon \& Voss (1999) pada tahun 90-an, laboratorium bahasa dipakai di berbagai kegiatan pembelajaran bahasa. Laboratorium bahasa tradisional seperti ini 
terdiri dari beberapa meja belajar (booths) yang berisi cassette deck, microphone, dan headphone. Dosen memonitor interaksi mahasiswa melalui central control panel. Melalui teknologi seperti ini dosen memberi model kepada mahasiswa, memberi penguatan, dan mahasiswa berlatih sendiri materi pembelajaran. Aktivitas pembelajaran dengan laboratorium bahasa seperti ini didasarkan pada pola perilaku stimulus-respon. Semakin banyak mahasiswa berlatih, semakin cepat pula mereka menguasai bahasa Inggris yang mereka pelajari. Meskipun laboratorium bahasa mampu menghubungkan secara positif teknologi dan pembalajaran bahasa, lambat laun aktivitas seperti ini terasa membosankan bagi mahasiswa. Selain itu, interaksi Dosen - pembelajar menjadi sedikit, dan pembelajaran individu dirasa kurang tepat. Alat-alat audio yang ada di laboratorium bahasa hanya berfungsi untuk menyampaikan suara saja. Hal-hal inilah yang menyebabkan perlunya pendekatan secara komunikatif dalam pembelajaran bahasa. Seiring dengan munculnya pemakaian (PC, tablet dan Handphone) dalam teknologi, maka pembelajaran bahasa juga mulai didukung dengan komputer (computer-assisted language learning (CALL).

Mikrokomputer dan CALL software selanjutnya menjadi media pengajaran sekaligus pembelajaran bahasa.Saat ini ada banyak pogram aplikasi komputer yang dapat dipakai dalam pembelajaran bahasa, yang menyediakan materi seperti: vocabulary, grammar, pronunciation tutor, spell checker, electronic books, writing and reading programs, dan bermacam-macam paket yang memungkinkan dosen membuat materi latihan sendiri sebagai suplemen terhadap materi yang telah ada.

Meskipun memiliki banyak kelebihan dibandingkan dengan media tradisional dan telah banyak diterapkan, CALL tetap saja memiliki kekurangan dan kritik. Menurut Armstrong \& Yetter-Vassot (1997) kebanyakan orang berpendapat bahwa belajar dan berlatih grammar bahasa asing melalui fill-inthe-blank exercise tidak banyak meningkatkan kemampuan mahasiswa dalam menghasilkan ujaran yang gramatikal. Selain itu, CALL juga memiliki kerumitan bahasa alami. Misalnya, program yang dirancang untuk latihan penguasaan kata kerja (verb) hanya dapat dipakai untuk latihan seperti ini, tidak yang lain.

Ketika internet mulai dipakai dalam teknologi komunikasi, internet mulai diperkenalkan ke pengajaran dan pembelajaran bahasa asing, karena dosen dan mahasiswa mulai mengenalnya. Oleh karena itu, makalah ini akan membahas beberapa pertanyaan: (1) Apakah internet itu?, (2) Bagaimanakah internet dapat dipakai sebagai media pembelajaran bahasa asing di lingkungan kampus, khususnya bahasa Inggris, dan (3) Apakah kelebihan dan kekurangan internet sebagai media pembelajaran bahasa Inggris?

\section{PEMBAHASAN 2.1.Internet}

Menurut kamus besar bahasa Indonesia secara harfiah, Internet (kependekan dari interconnected-networking) merupakan sistem global dari seluruh jaringan komputer yang saling terhubung menggunakan standar Internet Protocol Suite (TCP/IP) untuk melayani miliaran pengguna di seluruh dunia. Internet ialah sistem komputer umum, yang berhubung secara global dan menggunakan TCP/IP sebagai protokol pertukaran paket (packet switching communication protocol). Rangkaian internet yang terbesar dinamakan Internet. Cara menghubungkan rangkaian dengan kaedah ini dinamakan internetworking. Internet adalah jaringan komputer yang saling terhubung secara global yang memungkinkan pengguna internet saling 
bertukar informasi/data melalui jaringan tersebut. Internet adalah sistem komunikasi data berskala global, suatu infrastruktur yang terdiri dari hardware dan software yang menghubungkan komputer yang berada di jaringannya.

Dengan demikian internet berbicara mengenai jaringan komputer yang terhubung dan saling berinteraksi satu sama lain dalam skala global.

Menurut Sidharta (Kartal, 2005), walaupun secara fisik Internet merupakan interkoneksi antar jaringan komputer, secara umum Internet harus dipandang sebagai sumber daya informasi. Internet berisi informasi, yang dapat dibayangkan sebagai suatu database atau perpustakaan multimedia yang sangat besar dan lengkap. Bahkan Internet dipandang sebagai dunia dalam bentuk lain (maya) karena hampir seluruh aspek kehidupan di dunia nyata ada di Internet, seperti bisnis, hiburan, olah raga, politik, pendidikan, dan lain sebagainya. Internet merupakan sarana yang sangat efisien dan efektif untuk melakukan pertukaran informasi baik jarak jauh maupun di dalam lingkungan tertentu.

Beberapa layanan yang disediakan oleh Internet yang berbasis protokol TCP/IP adalah sebagai berikut:

\section{a. WWW (world wide web)}

WWW atau yang sering disebut web adalah aplikasi internet yang paling populer. Karena populernya sehingga banyak orang yang keliru mengidentikkan web dengan internet.Secara teknis web merupakan sebuah sistem informasi dalam bentuk teks, gambar, suara, dan lainnya yang tersimpan dalam sebuah internet web server yang dipresentasikan dalam bentuk hypertext. Informasi di web dalam bentuk teks umumnya ditulis dalam format html (hypertext markup language). Informasi lainnya disajikan dalam bentuk grafis atau gambar (format GIF, JPG, atau
PNG), suara (format AU, WAV), dan objek multimedia lainnya (seperti MIDI, Shockwave, Quicktime Movie, 3D World).

\section{b. Electronic Mail (E-Mail)}

E-mail atau surat elektronik merupakan aplikasi yang memungkinkan para pengguna internet saling berkirim pesan melalui alamat elektronik di internet. Para pengguna e-mail memiliki sebuah kotak surat (mailbox) elektronik yang tersimpan dalam suatu mailserver. Suatu mailbox memiliki sebuah alamat sebagai pengenal agar dapat berhubungan dengan

Mailbox lainnya, baik dalam bentuk penerimaan maupun pengiriman pesan. Pesan yang diterima akan ditampung dalam mailbox, sehingga pemilik mailbox sewaktu-waktu dapat mengecek isinya, menjawab pesan, menghapus, menyunting, atau menirimkan pesan e-mail.

Dalam The Turkish Online Journal of Educational Technology (2005) disebutkan beberapa manfaat yang diperoleh apabila seseorang mempunyai akses ke internet. Internet menyediakan:

a. Informasi untuk kehidupan pribadi, seperti: kesehatan, rekreasi, hobi, pengembangan pribadi, rohani, sosial.

b. Informasi untuk kehidupan profesional/pekerjaan, seperti pendidikan, ilmu pengetahuan, teknologi, perdagangan, saham, komoditas, berita bisnis, asosiasi profesi, asosiasi bisnis, dan berbagai forum komunikasi.

Penggunaan internet tidak mengenal batas negara, ras, kelas ekonomi, ideologi atau faktor - faktor lainnya yang biasanya dapat menghambat pertukaran pikiran. Kelebihan sarana internat yang tidak mengenal batas geografis juga 
menjadikan internet sebagai sarana yang ideal untuk melakukan kegiatan jarak jauh, baik melalui kursus tertulis maupun perkuliahan.

\section{c. Internet Sebagai Media Pembelajaran Bahasa Inggris}

Dalam The Turkish Online Journal of Educational Technology (2005) sebagai media komunikasi global, Internet memungkinkan untuk digunakan dalam konteks pengajaran dan pembelajaran bahasa, misalnya bahasa Inggris. Internet menyediakan berbagai alamat (sites) dan web pages yang dapat digunakan sebagai tempat belajar. Web pages tersebut sudah dikelompokkan menurut domain - nya, seperti vocabulary, grammar, phonetics, dan menurut keterampilan bahasa yang diajarkan, seperti speaking, listening, reading, dan writing.

Selain itu ada pula beberapa web pages yang mengkhususkan pada penyediaan buku ajar (text books) atau metode pengajaran. Bahan - bahan pembelajaran tersebut disajikan beragam: ada yang gratis, ada pula yang komersil.

Cord-Mounouray seperti yang dinyatakan dalam The Turkish Online Journal of Educational Technology (2005) mengelompokkan kegiatan belajar yang ditawarkan oleh Internet kedalam beberapa tipe:

a. Komunikasi:

proyek

korespondensi, pembelajaran jarak jauh, penelitian bidang tertentu dalam masyarakat internet, virtual meeting, role - play, dll.;

b. Dokumentasi: penelitian dokumenter, penyediaan pembaca dengan berbagai sumber yang diperlukan;

c. Penerbitan: penerbitan naskah (pribadi atau kolektif) baik yang sudah ada di internet maupun yang belum pernah ada; d. Studi kolaboratif: kompetisi, pentas bersama, collaborative writing, simulasi, tele-presence;

e. Studi individual: pembelajaran online, virtual campus.

Selain itu, ada tiga jenis sumber belajar yang berkenaan dengan pembelajaran bahasa di Internet, yaitu:

a. Sumber yang berhubungan institusi: pusat kajian, asosiasi dosen, editor, dll.;

b. Sumber dokumenter: kamus on-line, media, daftar pustaka, daftar link hypertext, dokumen untuk dosen, dll.;

c. Sumber untuk belajar: latihan interaktif, buku pelengkap, aktivitas belajar kelompok, situs untuk korespondensi, dll.

Dalam The Turkish Online Journal of Educational Technology (2005) juga diterangkan bahwa internet memiliki peran penting dalam pengajaran dan pembelajaran bahasa Inggris. Fungsi yang dapat dijalankan Internet dalam pembelajaran bahasa Inggris diantaranya adalah sebagai berikut:

a. Internet membantu pembelajar bahasa Inggris untuk mengakses sumber - sumber belajar yang berguna dan mengkomunikasikannya secara langsung dengan penutur asli.

b. Pembelajar dapat mempraktekkan penerapan informasi dan memecahkan kesulitan dalam belajar bahasa Inggris.

c. Pembelajaran dapat belajar listening, speaking, reading, dan writing secara terpadu melalui situasi dunia nyata.

Selain fungsi - fungsi tersebut, Internet juga memiliki aspek - aspek khusus pembelajaran bahasa berikut: 
a. Internet meningkatkan pemakaian bahasa.

b. Internet memperlancar komunikasi sinkronis dan asinkronis pembelajar, dan

c. Internet membantu pembelajar menggunakan bahasa dalam situasi komunikasi yang nyata.

d. Internet mampu merubah peran interaksi dosen - pembelajar dari teacher - centered ke learner centered

e. Internet memiliki materi otentik yang mudah ditampilkan, diakses, dan digunakan.

f. Internet juga memungkinkan pembelajar mempelajari budaya asing secara nyata.

g. Internet mampu meningkatkan berpikir tingkat tinggi.

h. Internet memungkinkan pembelajar memiliki keterampilan komputer yang baik.

i. Internet memungkinkan pembelajar mengenal berbagai macam wacana dan menggunakan bahasa lebih kompleks.

Dengan demikian dapat dikatakan bahwa Internet telah membawa dimensi dan kesempatan baru kepada pembelajaran bahasa Inggris dalam aspek komunikasi, interaksi kelas, dan materi yang otentik. Meskipun Internet menawarkan berbagai kemudahan dan kebaikan bagi praktek pembelajaran bahasa Inggris, bukan berarti bahwa tidak ada masalah atau kendala dalam pelaksanaannya. Ada beberapa masalah yang mungkin timbul dalam pemakaian Internet sebagai media pembelajaran bahasa Inggris, seperti (Singhal, 1997) kemukakan.

a. Akses internet oleh banyak pengguna pada jalur dan waktu yang sama akan membuat akses jadi lambat. Hal ini memungkinkan timbulnya rasa frustasi pada pembelajar. b. Kurangnya keterampilan dan pelatihan bagi dosen dalam mengoperasikan komputer akan membuat penerapan internet dalam pengajaran bahasa Inggris menjadi sulit diterapkan.

c. Biaya pengadaan fasilitas komputer, pelatihan komputer, dan akses internet yang tinggi hanya dapat dijalankan pada kampus - kampus tertentu yang memiliki dana yang cukup. Akibatnya, kampus dengan dana minimal tidak memungkinkan menerapkan penggunaan internet dalam pembelajaran di kelasnya.

d. Ada beberapa informasi di internet yang tidak sesuai dengan tingkat perkembangan anak didik. Ketiadaan program yang mampu memfilter informasi seperti ini bagi anak didik akan menjadi ancaman bagi pendidikan anak.

\section{PENUTUP}

Internet sebagai sebuah sistem jaringan global antar komputer telah memungkinkan penyebaran dan pertukaran informasi secara cepat tanpa ada batas geografis. Internet yang pada prinsipnya adalah alat komunikasi antara manusia sangat potensial dipakai dalam pembelajaran bahasa asing, termasuk bahasa Inggris. Internet membantu pembelajar bahasa Inggris untuk mengakses sumber-sumber belajar yang berguna dan mengkomunikasikannya secara langsung dengan penutur asli. Dengan demikian pembelajar dapat mempraktekkan penerapan informasi dan memecahkan kesulitan dalam belajar bahasa Inggris. Melalui internet pembelajaran dapat belajar listening, speaking, reading, dan writing secara terpadu melalui situasi dunia nyata.

Sebagai media modern dan multiguna, internet tentu saja juga 
memiliki keterbatasan, khususnya dalam penerapannya dalam pembelajaran bahasa Inggris di kelas. Keterbatasan penggunaan internet dalam pembelajaran bahasa Inggris antara lain: rasa frustasi ketika akses lambat, kurangnya keterampilan dosen dalam pemakaian komputer dan internet, biaya instalasi dan akses yang mahal, dan tidak semua informasi di internet sesuai dengan tingkat perkembangan anak.

\section{DAFTAR PUSTAKA}

[1] Alatis, James E. "The Essentials of Language Teaching". Diunduh 7 Maret 2018 dari www.nclrc.org/essentials

[2] Anonim. 2011. "Pengenalan Internet". Diunduh 8 Maret 2018 dari http://www.free.webs.com/nu2c/4p.Internet.pdf

[3] Boyanova, M. 2011. "English - the International Language". Diunduh 25 Februari 2018 dari http://www.studyenglishtoday.net/engli sh_language.html

[4] Singhal, Meena. 1997. "The Internet and Foreign Language Education: Benefits and Challenges". The Internet TESL Journal, Vol. III, No. 6, June 1997. Diunduh 13 Maret $2010 \quad$ dari http://itesjl.org/Articles/SnghalInternet.htm

[5] Kartal, Erdogan. 2005." The Internet and Autonomous Language Learning: A Typology of Suggested Aids". The Turkish Online Journal of Educational Technology -TOJET, Vol. 4 No. 4. 2005. pp. $54-58$ 